\title{
Thought Experiments and Novels
}

\author{
Tony Milligan
}

Department of Theology and Religious Studies, King's College London, United Kingdom

e-mail: anthony.milligan@kcl.ac.uk

\begin{abstract}
:
Novels and thought experiments can be pathways to different kinds of knowledge. We may, however, be hard pressed to say exactly what can be learned from novels but not from thought experiments. Headway on this matter can be made by spelling out their respective conditions for epistemic failure. Thought experiments fail in their epistemic role when they neither yield propositional knowledge nor contribute to an argument. They are largely in the business of 'knowing that'. Novels, on the other hand can be an epistemic success by yielding 'knowledge how'. They can help us to improve our competences.

Keywords: thought experiments, knowing how, knowing that, emotion, impoverished narratives
\end{abstract}

\section{I.}

Novels and thought experiments, or at least good instances of both are exercises of the imagination. Often (but not always) they are also fictional, involving counterfactual (imagined) rather than realized, circumstances. Both may escape the charge of fantasy by helping us to attend to real features of the world. My concern here will be to arrive at a rough story about what separates the two. Beyond saying that I am using 'thought experiments' to refer to impoverished narratives (rather than novels), I have no provisional definition to offer detailing what a thought experiment is. Nor is such a definition necessary in order to say something of interest about thought experiments. None of the available definitions look particularly promising. To say that thought experiments are experimental marks no obvious boundary, given that good novels are also in some sense experimental. Marking the distinction by appeal to non-execution is no more successful. If we can make sense of thought experiments as experiments without execution (Sorenson's position) then we can probably do the same for novels. ${ }^{1}$

We may even wonder if there is any point in marking a boundary here at all, especially when there is a senses of 'thought experiments' in which some novels could qualify. ${ }^{2}$ To be a thought experiment in the relevant, less restricted, sense just is to be an appeal to some counterfactual circumstance in order to explore and/or help to answer a question. Obvious examples of novels that are experimental in this sense would be most of the works of Dostoevsky and existentialist novels exploring the relation between freedom and anxiety. Other examples of novels that might count as thought experiments in this broad sense are works of science fiction where what 
if? questions about physics, time travel and freewill are central to the plotline. Some of the works if Stephen Baxter would qualify. A final and more unusual example of novelistic thought experiment is David Lodge's Thinks, unusual because thought experiments from Alan Turing, John Searle and Frank Jackson figure directly within the text. The very idea of thought experimentation is central to the narrative.

I do not intend to dispute the claim of such texts to be thought experiments in some sense, but it is just not the sense that interests me here. Instead, I will be concerned with thought experiments in a familiar but more restricted sense which requires that they are puzzle-like and brief. Here, it is their brevity that will principally be my concern. Thought experiments (in the relevant restricted sense) consider some specific scenario and only that scenario, with minor allowances for presentation. As in formal arguments aiming at deductive validity and soundness, the procedure when constructing thought experiments is to allow for some elegance of formulation while avoiding excess of detail. The reader is informed of the salient facts but they are informed of little else. Engaging in thought experimentation of this sort is a characteristic part of certain kinds of science (such as physics of a very theoretical sort) and also of analytic philosophy although both disciplines have skeptics about their methodological value. In the absence of any provisional definition, an example of this type of thought experiment may serve as a clarification of the kind of impoverished narrative that I have in mind:

Crusher and flusher: You enter a room, at one end of the room is a timed and loaded baby crusher, rather like a small textile press, and at the other end of the room is a timed and loaded embryo flusher. You have, and are aware of having, enough time to race over and switch off one device but not both. The crusher threatens a single infant, but the flusher threatens several embryos. What would you do?

This is a question that may have a serious point, but that does not make it a serious question. We would all rescue the baby on pain of moral idiosyncrasy and gross moral failure. And we would do so just so long as the given information is all that we have to go on. This thought experiment uses a briefly described scenario (an impoverished narrative) to help us recognize an intuition about what we value most. It is, in Daniel Dennett's familiar but rather awkward terms an 'intuition pump' [5]. It helps bring to the surface or otherwise to articulate a conviction that we may not previously have recognized ourselves to have. Such articulation can be a philosophically significant activity.

More ambitiously, it may be claimed that the above crusher-and-flusher experiment is (or contributes to) a concealed argument, with an implicit conclusion and one or more hidden premises. ${ }^{3}$ Someone who claims that each and every individual human embryo has the same value as each and every individual post-natal human, on running through the above brief narrative and taking on board its significance, might discover that there is something askew with their viewpoint or at least with an unqualified statement of it. The concealed argument in this particular instance has the structure of a reductio (absurd consequences follow from a given set of premises) but my case does not require commitment to the view that the argument concealed within the narrative of a TE must always have this structure.

\section{II.}

To say that novels are also counterfactual explorations is not to say that they must be in some sense arbitrary, or must lack anything approximating to an internal necessity where all the events are required by the narrative. As explorations of counterfactual circumstances, novels may even seem to have the edge over impoverished narratives of the sort involved in thought experimentation. What I have to say will aim to show one respect in which philosophical appeals to thought experiments are methodologically weaker than novels and not just methodologically distinct. My choice of the terminology of 'impoverished' expresses an acceptance that there is indeed a deficit. Martha Nussbaum, who has the works of Proust and Henry James in mind as members of the 
relevant contrast class, tries to cash out just what this deficit is by listing the failings of what she calls "schematic philosophers' examples." Their limitations contrast with the success-making features of good novels:

They almost always lack the particularity, the emotive appeal, the absorbing plottedness, the variety and indeterminacy, of good fiction; they lack too, good fiction's way of making the reader a participant and friend... If the examples do have these features, they will, themselves, be works of literature [13, p. 46].

Although she allows elsewhere that novels can be thought experiments I will take it that what Nussbaum means by "Schematic philosophers' examples" will overlap with what I mean by thought experiments in the relevant, puzzling and impoverished narrative sense. ${ }^{4}$ One of Nussbaum's points strikes home particularly well. We do not, or do not normally respond emotionally to thought experiments in the way that we do to novels and to literary fiction in general. There is no parallel to the paradox of fiction (the arousal of emotions about non-events) that needs to be dealt with. In the crusher-and-flusher case, life and its destruction are supposedly at issue, just as they are in novels where characters face decisions about abortion. But anyone who reacted with fear, sympathy or pity that was about this particular counterfactual case (and not just causally connected to it) would have to be in a peculiar delusional state. We can offer partial explanations of just why we experience emotions in response to novelistic (and other sorts of) fiction, but the same does not usually seem to apply to thought experiments.

It is conceivable that someone might think this an advantage, i.e. they might hold that thought experiments are in some sense less prone to induce false emotionally-swayed appraisals of what there is. However, with Nussbaum, we may (perhaps more plausibly) be inclined to regard it as a genuine deficit, at least in cases where thought experiments concern moral responsiveness rather than issues of physics. If one holds to a cognitive account of the emotions, whereby they involve beliefs or a belief-like construal of how things stand with humans, this absence of an emotional response may indicate that something somewhere is lacking in thought experiments. If they do not induce emotional responses then it looks like the scenarios that they involve cannot be realistic enough, or else that they may be sufficiently realistic but somehow they still manage to induce emotional oversight.

Nussbaum adds a further interesting wrinkle to this picture to the effect that at least some schematic philosophers' examples may have enough of the relevant features to count as works of literature (in the relevant restricted sense of 'works of literary fiction') and presumably this would include their having some sort of emotive standing. In support of this claim she footnotes Iris Murdoch's use of examples in The Sovereignty of Good [13, p. 46, n. 84]. I will take it that she has Murdoch's case of D and M in mind. (Nothing else in Murdoch's Sovereignty fits the bill.)

\section{The Case of D\&M}

A mother, who I shall call M, feels hostility to her daughter-in-law, whom I shall call D. M finds D quite a good-hearted girl, but while not exactly common yet certainly unpolished and lacking in dignity and refinement. D is inclined to be pert and familiar, insufficiently ceremonious, brusque, sometimes positively rude, always tiresomely juvenile. M does not like D's accent or the way D dresses. $M$ feels that her son has married beneath him. Let us assume for the purposes of the example that the mother, who is a very 'correct' person, behaves beautifully to the girl throughout...Thus much for M's first thoughts about D. Time passes, and it could be that M settles down with a hardened sense of grievance and a fixed picture of D...However, the $\mathrm{M}$ of the example is an intelligent and well-intentioned person, capable of self criticism, capable of giving careful and just attention to an object which confronts her. M tells herself: 'I am oldfashioned and conventional. I may be prejudiced and narrow-minded. I may be snobbish, I am certainly jealous. Let me look again.' Here I assume that M observes D 
or at least reflects deliberatively about $\mathrm{D}$, until gradually her vision of $\mathrm{D}$ alters...And as I say, ex hypothesi, M's outward behaviour, beautiful from the start, in no way alters [11, pp. 16-17].

This thought experiment can help the reader to articulate or recognize the intuition that we can be active in a morally praiseworthy manner without engaging in publicly-observable behavior. Inner and morally significant events may stand in no need of an outer criterion. D\&M also succeeds in the more generous terms that Nussbaum allows. It is an impoverished narrative of a sort that could be enriched and worked into the plotline of a novel. Indeed there is one Murdoch novel (Bruno's Dream) in which a reworked version of the scenario does happen to be played out. ${ }^{5}$ But even were this not to be the case, D\&M already looks like a work of literature in miniature.

Moreover, while sympathy or compassion would be inappropriate responses to crusher-andflusher, it is not obviously the case that we can say the same about D\&M. It is intelligible that someone who has considered and weighed-up the example over several years might at least believe themselves to experience a mild degree of sympathy or compassion for $\mathrm{M}$. And while we might question whether their first-person report was accurate, and whether the compassion or sympathy, if present, was about $\mathrm{M}$ rather than about non-fictional persons in similar predicaments, we could equally well do the same in the case of any emotional response claimed by the reader of a novel [20, pp. 9-10].

Accordingly, when it comes to inducing an emotional response, Nussbaum seems to have good reason to avoid over-generalizing and to allow that some schematic philosophers' examples/thought experiments might make it into the literary fold. D \& M looks very different from crusher-and-flusher, less impoverished and more familiar. We can see how it could be embedded within a background of normal life and this is just what we cannot do in the crusher-and-flusher case. It is a scenario that isolates itself off from the normal, richly detailed background of our world, the detail that might legitimate an emotional response. In that sense it is analogous to experimentation under isolated laboratory conditions.

However, while we might at least entertain the idea that suitably constructed thought experiments can induce an emotional response in normal rational agents, and that this response can be in keeping with the rational character of these agents, it would be odd if thought experiments were to expand the emotional repertoire of such agents in any direct manner. And this is something that novels seem to be capable of doing [14, pp. 236-237]. Someone who lacked compassion could begin to grow through their encounter with literary characters, through their becoming familiar for the first time with the kind of joined-up narrative on which so much of the experience of compassion depends. It is a familiar point made by both Nussbaum and Murdoch that when encountering characters in novels we take the time to attend that we often do not take with the individuals that we encounter in everyday life. This may be, in part, because of the differences between novels and everyday life: it is easier for us to attend when there is less at stake and when the overall experience is likely to be enjoyable. But this is often how we learn, in the easier context first.

Be that as it may, whatever the limits of the compassion between attending to a character in a novel and attending to a non-fictional other, novels still seem to make possible the cultivation of a new pattern of emotional response through the patient disclosing of details that we would ordinarily, impatiently or inattentively overlook. Allowing for the possibility of some rare exceptions, even a thought experiment such as D \& $M$ that provides scope for genuine emotional response, is likely to do so by drawing upon an existing pattern of emotional response and an existing repertoire of emotions, rather than by expanding our repertoire or by otherwise altering our pattern of response.

III.

This is a difference that I take to hold in most cases, on the whole, or generally speaking. It is not 
itself the loose boundary marker that I want to situate but it may be symptomatic of the fact that it $i s$ appropriate to place some boundary marker between novels and thought experiments. The marker itself will be set down as follows. Novels and thought experiments, or rather good instances of either, can play an educative i.e. knowledge-generating role. But in the case of novels what we learn can be competences or skills for encountering the other, and this is something rather different from the propositional knowledge that both thought experiments and novels can help us to acquire.

The difference may perhaps be better appreciated if we reflect upon the respective conditions for epistemic failure of the two kinds of narrative. In the case of thought experiments the conditions for epistemic failure are, up to a point, clear cut. A thought experiment fails when it neither helps to articulate some intuition nor functions as a concealed argument (or as a contribution to such an argument). And to say this much is to make it clear that thought experiments are primarily concerned with knowing that something is the case. Moreover, this knowledge that usually concerns something general. It is not just relevant to the peculiar circumstances that the experiment happens to specify. ${ }^{6} \mathrm{We}$ are not ultimately concerned to know that in the crusher-andflusher scenario we would do or ought to do one thing rather than another. We are concerned to know that on pain of moral idiosyncrasy we value or ought to value individual infants more than collections of individual embryos and that we should act accordingly.

My point here is that thought experiments in moral contexts, but not only in moral contexts, can allow us to make rule-like generalizations. And it is this generality that helps to explain why those who stress the importance of the particular (again Martha Nussbaum, Cora Diamond and Iris Murdoch) together with those who reject guidance by moral principles (particularists such as Jonathan Dancy) are also critics of appeals to schematic thought experiments in moral contexts [3]. As a first approximation we can say that when a thought experiment does not function as, or contribute to, a concealed argument and fails to yield (i.e. to promote our identification and acceptance of) some appropriate generalizing proposition it is an epistemic failure. And here we need not require that the thought experiment yields what its author claims that it yields. An experiment that fails to show what its author claims is not thereby automatically a failure but if it fails to contribute to any argument or to yield any appropriate generalizing proposition then it $i s$ an epistemic failure.

As a slightly modified version of the above claim we might allow that thought experiments sometimes help us to learn new concepts or to refine existing concepts rather than, or as well as, helping us to acquire knowledge that. According to Kuhn some thought experiments do not yield propositional knowledge but help to generate a paradigm shift involving some form of conceptual change or refinement. ${ }^{7}$ This may be a rare matter, but I see no reason to deny that something of this sort may from time to time occur. If we accept this, and accept that conceptual acquisition or refinement can count as knowledge acquisition, then our account of the conditions for epistemic failure will take the form of a conjunction. Where a thought experiment is not a concealed argument or a contribution to such an argument and where it also fails to pump out or give reason for some appropriate generalizing proposition and has no disposition or tendency to improve our conceptual repertoire then it is an epistemic failure. And while it might succeed in some other way, for example as a source of amusement or as a good way to loose some time on a train, it is not a success as $a$ thought experiment.

If we assume that novels play an educative role they too must have conditions for epistemic success and failure. But these conditions are not simply a matter of failing to yield or contribute to knowledge that. Indeed, a good novel by an analytic philosopher (if we can stretch our imaginations far enough to allow for such a possibility) might well be one in which the author looses sight of her usual concern to sharpen up intuitions and to generate sound or valid arguments. Novelistic success for such a remarkable being might come at the price of failing to deliver just what a thought experiment must usually deliver if it is to be a successful thought experiment.

Nevertheless, as they are works of the imagination, novels which fail comprehensively from an epistemic point of view, which fail in any important sense to help the reader attend to real features of the world, are works of sheer fantasy. (Here I use 'fantasy' in a way that contrasts with 
imagination and is different from its use in the shelving classification 'fantasy literature'). Good novels open up possibilities of knowledge, but often it is knowledge of a different sort from that promoted by consideration of a thought experiment. Sometimes, and perhaps often, these two kinds of narrative are not rival pathways to the same thing. It would, for example, be odd under many circumstances to turn to a novel to gain certain kinds of non-trivial knowledge that. We might of course, turn to a novel to get trivial knowledge or knowledge concerning the novel itself. Someone might have to get up to speed on a particular text for a lecture or exam, or for typesetting or statistical purposes they might want to know the exact number of times the letter ' $q$ ' is used in a text. But setting aside such matters, novels are not systematically in the business of making available this kind of knowing that. If we want to know that utilitarianism involves claims $\mathrm{x}$ and $\mathrm{y}$ we might turn to Dickens' Hard Times, but we would not usually do so. Nor would we usually recommend this procedure to others. Perhaps more importantly, we could not defensibly say that it was the kind of novel from which we can learn nothing of philosophical importance if its account of utilitarianism happens to be skewed or otherwise uncharitable (which it is).

This is not to say that we can never gain knowledge that from novels but rather to say that acquisition of this kind of knowledge is often something of a bonus. If we want to know that such and such an event happened at the battle of Austerlitz we would not normally turn to Tolstoy, but we might turn to the death of Petya Rostov in War and Peace or to Ivan Ilych if we want to know that encountering death can involve experiences of some particular kind. And here knowing that and conceptual acquisition or refinement may go hand in hand. We may learn something about what grief involves by reading the novels in question. And it may even be that conceptual refinement is a regular part of reading novels of the best sort in a way that is not the case for thought experimentation. Nevertheless, we can appropriately regard a novel as an epistemic success without making any appeals to knowledge that or to conceptual acquisition and refinement. Even if we come away with no new information, no new propositional attitudes, or with no deeper understanding of some concept, we may still have learned something.

What I want to suggest is that the other sort of knowledge made available by novels is the same type of knowledge that may arguably be gleaned from the most interesting mystical texts. They may contain all sorts of literal falsehoods, ambiguities and occasional nonsense, but some of those who study such texts do seem to be unusually competent humans and do seem to have learned something. Although, here we might wonder if their competences are in part the result of reading the texts or if they diligently read the texts because of competences that they already possess. (I make this claim only as a way of putting matters that will clarify matters for some readers.)

A similar claim about the acquisition of competences, perhaps a less controversial one, but still controversial up to a point, may be made in relation to texts by Derrida. ${ }^{8}$ Once we have a grasp of the big themes that are repeatedly worked upon and may be set out more or less lucidly in propositional form, we can still learn something else from such texts but we might be hard pressed to say exactly what we learn. I want to suggest that in such cases what we can gain, or what the attentive diligent reader can gain, is knowledge how by contrast with familiar forms of knowledge that.

Reading a mystical tract, or Derrida (and these two activities may sometimes be one and the same) can help to teach us how to encounter uncertainty and indeterminacy with fresh eyes. That is to say, it can improve the quality of our practical reason with the latter understood in a sufficiently rich sense and not reduced to an ability to terminate arguments with actions. We can gain knowledge of how to cope with, how to realistically encounter tracts of experience that do not offer themselves up with clear signposts or assembly instructions. Similarly, and here I make a familiar point that is associated at least with Nussbaum and Murdoch, both the authoring and the reading of novels involves a succession of exercises of attention. The reading of good novels can educate us in how to attend to the particularity of what is other, how to do so patiently and justly. If we are unwilling to engage with characters who are in some respect unattractive we will not get the enjoyment that we otherwise would from the reading experience. A good novel is one that may involve moral ambiguity so that we cannot just privately boo the villains and cheer the heroes. It 
may also require that the characters have genuine particularity and are more than recognizable stereotypes for some or other character trait, virtue or flaw. ${ }^{9}$

Here, as opposed to the case of Derrida's texts where an instructive mysticism is in play, we are clearly in territory where the gain in knowledge is of a morally relevant sort. It is knowledge how of a sort that may figure in moral education. Attending patiently to flawed individuals (and we are all flawed individuals) is not something that we ordinarily do well, or that we know how to do by default. To know how to do this is an epistemic accomplishment that is not an ordinary part of our socialization. Moreover, learning to respond to particularity is itself, in one sense, also a general competence, something that can be carried from situation to situation. And in this respect we may be said to learn something of general applicability in the case of diligently reading novels, just as we learn something general (often of a different sort) from a thought experiment. In the one case we may acquire a general principle and in the other a generally applicable skill.

To state matters in a more concrete manner consider the following situation. A teenager is given a copy of Dickens' Little Dorrit and that this is their first big book. They might come to admire the supply of patience that the little seamstress Amy Dorrit appears to have. They might come to learn the general lesson that patience is or can be a very admirable thing and that it is required if we are to do justice by the other. However, this is not at all the same as actually becoming more patient as a result of reading the book. Yet the latter is also a possibility. Little Dorrit is, after all, a substantial volume and a good deal of the detail is not strictly helpful to the plot. To get through it the teenager may have to effortfully stick at it and not give up. And it is in the application of this effort that they may learn to become more patient and also learn to self-trust with regard to seeing things through to the end. As well as this, there is a sense in which such a reader may also enrich their grasp of what patience involves. And these epistemic gains are different from learning that patience is or can be admirable. Indeed, the gains might equally well might be made by reading a large and challenging novel in which patience does not figure directly as a theme. But to say this is not to claim that a long novel cannot fail to cultivate patience. Whether it does so or not will depend, in part, upon its being sufficiently engaging to give the reader some reason to keep going. (Generations of readers have happened to find Little Dorrit engaging in the relevant manner. Proust's Recherche would be an extreme example of patience cultivated and rewarded.) And so, there may be an intimate connection between novelistic content and the potential of any novel to help the reader acquire knowledge how.

\section{IV.}

The above goes some way towards giving an account of what it is that good novels do and that thought experiments do not do. Literature helps to improve the quality of our practical reason and this gives some justification (if justification were ever needed) for the claim that philosophers, or at least moral philosophers, ought to read and engage philosophically with novels as a regular part of their philosophical practice. However, I have set up this contrast between novels and thought experiments by appeal to a knowing how/knowing that distinction which may seem vulnerable to familiar suspicions concerning overly-clean and clear-cut distinctions. This suspicion is at work, for example, when Iris Murdoch writes against a demand for precision where a tolerance for ambiguity may be less misleading [10]. Derrida writes in a similar, but more systematic vein, about the danger of shoring-up implausibly hygienic binary contrasts of a familiar and problematic sort, the sort that privilege one side of the contrast but then covertly rely upon the other side [6, pp. 41-42].

Here, I think that we can make a move that Hilary Putnam favors and highlight a difference between what we may call 'dichotomies' and what we may call 'distinctions'. ${ }^{10}$ Dichotomies purport to have complete generality. They may be rolled out across an entire field of enquiry. Distinctions claim no such dominion. They allow for a role to be played by classifying cases as instances of this or that but they also allow that there will be blurring in some or even many cases. And the contrast between distinctions and dichotomies may itself be of this sort. I will take it that what the Derridean critique legitimately targets is rigid dichotomies, and that rejection of these does 
not entail rejection of the distinctions that apply for the most part or only up to a point. In line with this, my appeal to a knowing how/knowing that distinction is not a suitable target for a Derridean critique.

Moreover, insofar as there is a problem of privileging one side of the contrast, it is the danger of privileging knowing that. ${ }^{11}$ Instead, I am trying to affirm the distinctive moral importance (which is not to say greater importance) of the kind of knowing how that novels can help us to cultivate. Indeed, when we think about morality, while it may be the case (as Murdoch's D\&M example suggests) that actions are not all that matters it is nonetheless still the case that actions do matter a great deal. Practical wisdom and competence to perform, both of which involve knowledge how, is not, from a moral point of view second rate.

With the distinction still available, and with knowledge how accorded appropriate standing, we can cash out one important feature of the contrast between thought experiments and novels. Thought experiments are (generally) geared to the production of propositional knowledge while novels, may yield knowledge that but they are also effective in the production of knowledge how, where the latter is to be understood as knowledge of a practical sort that happens to fit novels particularly well to the task of moral education.

A qualification here concerns one area of the overlap, where both kinds of narrative assist us in the refinement of our concepts. We might wonder about just what it is to gain knowledge how and if it is anything other than a form of conceptual knowledge. If it reduces to the latter then insofar as thought experiments are regularly capable of conceptual refinement there will be a kind of knowledge how that they will also be regularly capable of providing. But such a reduction does not look attractive. The following may be said against it: if I learn how to encounter others more realistically through the reading of novels, or in any other way, then I am, in a sense refining my grasp of what it is to be human and perhaps my grasp of various other (thick) concepts as well. I may deepen my grasp of what is involved in being just, generous or humble. But, on the other hand, if I learn how to ride a bike it is not so obvious that my concepts need to have altered. (Unless we have a very reductionist and dispositional account of what is involved in the mastery of a concept.) The former example suggests that acquisition of knowledge how may (and perhaps may often) involve conceptual acquisition or refinement. The latter case suggests that this is not always the case and that acquisition of knowing how cannot reduce to conceptual acquisition or refinement.

The upshot is that even when we allow that both novels and thought experiments may help us to make conceptual progress there still remains something significantly different about the range of epistemic roles that these differing kinds of narrative characteristically play. And this something different involves novels having a wider range of conditions for epistemic success or failure.

\section{References}

1. Bishop, M. Why Thought Experiments are Not Arguments Philosophy of Science 66, 1999).

2. Brown, J. R. The Laboratory of the Mind: Thought Experiments in the Natural Sciences, London: Routledge, 1991.

3. Dancy, J. The Role of Imaginary Cases in Ethics, Pacific Philosophical Quarterly 66, 1985.

4. Davies, D. Thought Experiments and Fictional Narratives, Croatian Journal of Philosophy 19, 2007.

5. Dennett, D. Intuition Pumps, In J. Brockman, The Third Culture: Beyond the Scientific Revolution, Simon \& Schuster: New York, 1995.

6. Derrida, J. Positions, Chicago: Chicago University Press, 1982.

7. Kuhn, T. A Function for Thought Experiments, In T. S. Kuhn, The Essential Tension, Chicago: University of Chicago Press, 1977.

8. Moore, A. W. Arguing with Derrida, Ratio 13 (4), 2000.

9. Murdoch, I. Sartre, Romantic Rationalist, London: Vintage, 1999.

10. Murdoch, I. Against Dryness, In I. Murdoch Existentialists and Mystics: Writings on Philosophy and Literature, P. Conradi (ed.), London: Penguin, 1999 
11. Murdoch, I. The Sovereignty of Good, London: Routledge, 2001.

12. Norton, J. Are Thought Experiments Just What You Always Thought? Canadian Journal of Philosophy 26, 1996.

13. Nussbaum, M. Love's Knowledge, Oxford: Oxford University Press, 1992.

14. Nussbaum, M. Upheavals of Thought, Cambridge: Cambridge University Press, 2001.

15. Putnam, H. The Collapse of the Fact/Value Dichotomy, Cambridge Mass.: Harvard University Press, 2002.

16. Regan, T. The Case for Animal Rights, Berkeley: University of California Press, 2004.

17. Sorenson, R. Thought Experiments, Oxford: Oxford University Press, 1992.

18. Stanley, J., and T. Williamson. Knowing How, Journal of Philosophy 98 (8), 2001.

19. Swirski, P. Of Literature and Knowledge: Explorations in Narrative Thought Experiments, Evolution and Game Theory, London: Routledge, 2006.

20. Walton, K. Fearing Fictions, Journal of Philosophy 75 (1), 1978.

\section{Notes}

1. According to Sorenson [17, p.205], a thought experiment is 'an experiment that purports to achieve its aims without the benefit of execution', but this would leave the genuinely experimental status of thought experiments open to question.

2. For a quite different treatment of extended fictional narratives as thought experiments (in a less constrained sense) see [4] and [19].

3. For the view that thought experiments are really arguments see [1] and [12].

4. Nussbaum's essay on 'Transcending Humanity' in [13] uses 'thought experiment' in a wider sense that is inclusive of novels and related works such as Homer's Odyssey.

5. In Murdoch's 1969 novel Bruno's Dream a father-in-law is confined to his deathbed and unable to do anything but reflect upon matters. He has to face his failure to welcome his daughter-in-law while there was still time, before her tragic death and his son's subsequent estrangement.

6. To allow that the knowledge in question does not simply concern the circumstances specified in a particular experiment is consistent with allowing various restrictions of the sort set up by Tom Regan to the effect that some thought experiments tell us what to do in exceptional cases and not in normal cases [16, pp. xxvii-xxx].

7. Kuhn [7] and for a contrasting classification of thought experiments as primarily concerned with theory refutation and support, see [2].

8. Moore [8, p.367 ff.], approaches Derrida from the standpoint that of 'knowing how' rather than 'knowing that' albeit his reason for doing so concerns the ineffable. I have no objection to this but an appeal to ineffability plays no direct part in my approach to the novel.

9. For the limited value of using character types in novels see Iris Murdoch's account of Sartre's Roads to Freedom trilogy in [9, p.56 ff].

10. See [15, pp. 9-11] for the contrast between 'distinctions' and 'dichotomies'.

11. This suspicion about knowing how is particularly evident in [18]. 